Letter to the editor

\title{
The game is not over for polio virus in India; it can strike back again
}

It was really great to read about efforts of Zaffran and coworkers on eradication of polio from globe and a big relief for health scientist. ${ }^{1}$ Simultaneously it was shocking to know and read about the administration of contaminated polio vaccine in three states of India Maharashtra, Uttar Pradesh and Telengana. Uttar Pradesh is one of the most densely populated states of India. As per the news only some vials were contaminated by type 2 polio virus and advisory is already issued on surveillance of all children that might have taken this vaccine by health Ministry. It is now a challenge for the health authorities to administer inactivated polio virus (IPV) injections to all such children and monitor the symptom and behavior pattern of the type- 2 polio virus. ${ }^{2}$

Out of total, $99.9 \%$ cases of polio has been removed from world but still there is an obstacle for making world free from polio. It was found that, many people who received one vaccine version in 2016, carry another mutated strain of polio virus. Mutated virus then spread in the area and affected others. ${ }^{3}$

For India it is tough to become polio free nation. It give challenge to the Indian system of healthcare. Prevalence of acute flaccid paralysis (AFP) which may be induced by mishandling of oral polio vaccine put country in health risk. Currently annual cases of AFP is greater than 50,000 then what is the meaning of Polio free country? ${ }^{4}$ In India, Uttar Pradesh and other states, disease and poverty are the main hurdle in polio vaccination than political, religious, culture. ${ }^{5}$ As per report of Times of India, minimum three polio vaccines batches which contain 1.5 lakh vials reported contaminated with polio virus type 2 . WHO and the Ministry of Health started surveillance, especially in Uttar Pradesh, Telangana and Maharashtra where cases of contaminated vaccines reported at large level. In Pharmaceutical companies of India Quality Control is also a matter concern. In India most of the pharmaceutical company standard fails on the scale of FDA. ${ }^{6}$ More new and effective strategies need to be developed and implemented in such cases if we really want to see world free from polio virus. Further the countries involved immunization programme of polio vaccine need to check once again on this issue.

\section{References}

1. Zaffran M, McGovern M, Hossaini R, Martin R, Wenger J. The polio endgame: securing a world free of all polioviruses. Lancet. 2018;391:11-13.

2. Hindustan Times. Contaminated polio vaccine given to children in Maharashtra, Telengana, UP. https://www.hindustantimes.com/india-news/contaminated-poliovaccine-given-to-children-in-maharashtra-telengana-up/storykYpVu3fYD73VWU1OpzYx7N.html; Oct, 2018, Accessed date: 10 October 2018.

3. Belluz J, Resnick Brian. A vaccine we don't even use anymore is a reason polio keeps spreading - yes, really. https://www.vox.com/science-and-health/2018/7/4/ 17530642/polio-vaccine-outbreak-drc-who; July 5, 2018, Accessed date: 11 October 2018.

4. Vallejo C, Keesling J, Koopman J, Singer B. Silent circulation of poliovirus in small populations. Infect Dis Model. 2017;2:431-440.

5. Samson K. Polio outbreak in northern India has global reach. Neurol Today, 2006;6(19):13-14.

6. Dey S. Contaminated vaccines put India's 'polio free' status at risk. https:// timesofindia.indiatimes.com/india/contaminated-vaccines-put-indias-polio-freestatus-at-risk/articleshow/66021197.cms; Oct 1, 2018, Accessed date: 11 October 2018.

Imran Kazmi*

Department of Biochemistry, Faculty of Science, King Abdulaziz University, Jeddah, Saudi Arabia E-mail address: kazmiimran2005@gmail.com.

Muhammad Afzal** Department of Pharmacology, College of Pharmacy, Jouf University, Sakaka, Kingdom of Saudi Arabia E-mail address: afzalgufran@gmail.com.

Muhammad Shahid Nadeem, Fahad A. Al-Abbasi, Firoz Anwar*** Department of Biochemistry, Faculty of Science, King Abdulaziz University, Jeddah, Saudi Arabia

E-mail address: firoz_anwar2000@yahoo.com (F. Anwar).

\footnotetext{
* Corresponding author.

** Corresponding author.

*** Corresponding author. Department of Biochemistry, Faculty of Science, King Abdulaziz University, Jeddah, Saudi Arabia.
} 